\title{
Evaluation of a Russian version of the oral health literacy instrument $(\mathrm{OHLI})$
}

\author{
Anastasiya Blizniuk, Masayuki Ueno*, Sayaka Furukawa and Yoko Kawaguchi
}

\begin{abstract}
Background: Oral health literacy has become a popular research area in the last decade; however, to date no health literacy instruments in the Russian language exist. The objectives of this study were to develop a Russian version of the Oral Health Literacy Instrument (OHLI) and to examine its reliability and validity.

Methods: A convenience sample of patients who visited the dental division of the district hospital in Belarus was used in the study. The OHLI, created originally in English, was modified to adapt it to characteristics of routine dental services in Belarus and then translated into Russian, followed by back-translation. Participants completed a self-administered socio-demographic questionnaire, an oral health knowledge test and the Russian version of the OHLI (R-OHLI). Bivariate and multivariate statistical analyses, including multiple regression modeling, were performed to examine reliability and validity of the R-OHLI.
\end{abstract}

Results: Participants were 281 adult patients aged from 18 to 60 years, with a mean age of $33.1 \pm 12.2 ; 64.1 \%$ of them were women. Cronbach's alpha values for the two sections (reading comprehension and numeracy) and the total R-OHLI were $0.853,0.815$ and 0.895 , respectively. The mean total R-OHLI score was $77.2 \pm 14.5$; the mean reading comprehension and numeracy scores were $39.5 \pm 7.5$ and $37.8 \pm 8.8$, respectively. The R-OHLI was significantly correlated to the oral health knowledge test. Pearson's correlation coefficients between the oral health knowledge test and the reading comprehension, numeracy and total R-OHLI were $0.401,0.258$, and 0.363 , respectively $(p<0.001)$. Women, participants with a university degree, and those who visited a dentist at least once a year had significantly $(p<0.05)$ higher mean scores for each section (reading comprehension, numeracy) and for total R-OHLI compared to their counterparts.

Conclusions: The R-OHLI showed good internal consistency and test-retest reliability. It was significantly associated with the oral health knowledge test, socio-demographic and behavioral factors. Therefore, the R-OHLI was proved to be a reliable and valid oral health literacy instrument for Russian-speaking people.

Keywords: Oral health literacy, Oral health literacy instrument (OHLI), Russian version, Validation studies

\section{Background}

The concept of health literacy has received significant research attention in the last decade. Health literacy is of particular importance when dealing with chronic conditions and life-style diseases [1,2]. Oral diseases are highly preventable, but they remain common in many countries throughout the world [3]. For oral health literacy, the definition of health literacy developed by Ratzan and Parker [4] was later adopted for use in the context of oral health. Oral health literacy is defined as the "degree in which

\footnotetext{
* Correspondence: ueno.ohp@tmd.ac.jp

Department of Oral Health Promotion, Graduate School of Medical and Dental Sciences, Tokyo Medical and Dental University, Tokyo, Japan
}

individuals have the capacity to obtain, process and understand basic oral health information and services needed to make appropriate health decisions"[5]. Oral health literacy is a complex concept, and its functional aspect can be described as a set of personal skills and abilities that enable oral health related knowledge acquisition and decision-making. For that reason, high oral health literacy is essential to improve people's awareness of oral disease, knowledge about methods of disease prevention and health maintenance, and to eventually lead people to desirable attitudes and behaviors.

Previous findings demonstrated that low oral health literacy was widespread and could explain certain inequalities 
in oral health [6-14]. A number of studies showed that limited oral health literacy contributes to poor oral health status $[10,14]$. People with lower oral health literacy are more likely to neglect prevention measures and seek emergency treatment [12]. Parents' or caregivers' oral health literacy affects children's oral health outcomes $[15,16]$. The majority of studies on oral health literacy have been conducted in North America [8-10,12,13,15-17] and some Asian countries $[11,14,18,19]$. The European office of the WHO reported in 2013 that nearly half of Europeans had "inadequate or problematic health literacy skills", but with great variance among countries [20]. These data suggest that oral health literacy levels in Europe may not be high; however, no systematic research data on oral health literacy are available [21]. The scarcity of oral health literacy information requires more research to be done in these countries.

Oral health related jargon is specific and differs from the terms used in general medicine, leading to the development of specific tests measuring an ability to understand dental terms and oral health related information. Further, because the majority of studies on oral health literacy were produced in the USA, existing oral health literacy assessment instruments are predominantly in English. There are two main strategies to evaluate oral health literacy: word recognition and reading comprehension. Word recognition instruments (REALD-30, REALD-99, REALM-D, TS-REALD, HKREALD-30) [7,18,22-24] were created first and concentrated on a respondent's ability to correctly pronounce oral health related vocabularies. Reading comprehension tests, such as the TOFHLiD, OHLI, OHL-AQ, HKOHLAT-P $[17,18,25,26]$ were constructed to evaluate functional literacy, and, therefore, measured a person's ability to understand and apply written information, including numerical data. Macek's comprehensive oral health knowledge test (CMOHK) [13] aimed to assess oral health literacy levels through measurement of conceptual oral health knowledge. Quite a large number of instruments exist, but none of them is adequate to measure all dimensions of oral health literacy. Although most were developed in English [13,17,22-25], several oral health literacy instruments are available in Spanish, Persian and Chinese $[18,19,26,27]$. However, to date there is no health literacy instrument in Russian, which is the native language for 162 million people living in 16 countries [28].

It is difficult to apply English word-recognition instruments to other languages due to certain linguistic differences [27]. For that reason we chose reading comprehension as a method for oral health literacy assessment. At the time of developing the study design, only two reading comprehension instruments existed: the OHLI [17] and the TOFHLiD [25]. The OHLI was chosen to develop an instrument for Russian speakers because of its better reliability and validity than the TOFHLiD $[17,25]$. Moreover, the cloze procedure, on which the OHLI is based, has been widely used and proved to be effective for reading comprehension assessment in Russian [29].

The OHLI is a validated functional literacy test, measuring not only reading comprehension but also numeracy ability [17]. The objectives of this study were to develop a Russian version of the OHLI and to examine its reliability and validity.

\section{Methods \\ Subjects}

The study was conducted using a convenience sample of adult patients who visited the dental division of the district hospital in Belarus during July and August of 2013. Adult patients aged 18-60 years, and without physical or mental disabilities, were asked to participate in this study. A written informed consent was obtained from each participant. Patients older than 60 years were excluded to create a homogenous sample. We were granted permission to conduct the survey by the hospital's administration. The research protocol was also approved by the Tokyo Medical and Dental University Ethical Committee prior to data collection (Approval No 901).

\section{Questionnaire}

A self-administered questionnaire was used to collect information about socio-demographics (gender, age, education - junior high school, high school or university level) and oral health behavior (regularity of dental visits less than once a year or once a year and more).

\section{Oral health knowledge test}

The oral health knowledge test applied by Sabbahi, et al. to validate the OHLI [17] was created in accordance with the information used in education materials in Canada. There were certain difficulties in its application to the Belarusian population, because the prevalence of oral disease and oral health conditions, as well as routine dental treatment procedures, in Belarus differed significantly. For that reason, we developed a new oral health knowledge test that followed the actual oral health situation and referred to oral health related materials in Belarus. The oral health knowledge test used in the study included 10 statements regarding dental caries, periodontal disease, oral cancer and oral hygiene (Table 1). Subjects were asked to score each statement as true or false; correct answers were scored with 1, incorrect or don't know answers were scored with 0 . Total oral health knowledge scores ranged from 0 to 10 (the sum of scores for each item). Oral health knowledge test's scores were multiplied by 10 to create a weighted scale from 0 to 100 (100/10). 
Table 1 Oral health knowledge test

\begin{tabular}{|c|c|c|c|c|}
\hline 1 & Dental decay is caused by the bacteria of the oral cavity & true & false & don't know \\
\hline 2 & Sweet food and drinks have positive effect on the teeth & true & false & don't know \\
\hline 3 & Use of fluoride makes the teeth stronger & true & false & don't know \\
\hline 4 & Sealants are dark spots on the teeth & true & false & don't know \\
\hline 5 & Dental plaque causes periodontal diseases & true & false & don't know \\
\hline 6 & There is no relationship between periodontal diseases and diabetes & true & false & don't know \\
\hline 7 & It is necessary to use a dental floss every day to clean between the teeth & true & false & don't know \\
\hline 8 & The teeth should be brushed at least twice a day & true & false & don't know \\
\hline 9 & Cancer cannot appear in the oral cavity & true & false & don't know \\
\hline 10 & Visiting a dentist once a year helps to preserve oral health & true & false & don't know \\
\hline
\end{tabular}

\section{R-OHLI}

The R-OHLI is a Russian-language version of the OHLI, created originally in English by Sabbahi, et al. (2009). The OHLI is a functional oral health literacy test based on the TOFHLA [30], and consists of cloze-procedure based reading comprehension and numeracy sections. The reading comprehension section has 38 items and assesses the individual's ability to read and understand written information about dental disease. Words were omitted from 2 passages, one on dental caries and the other on periodontal disease. The numeracy section has 19 items and evaluates the individual's ability to comprehend common dental medication prescriptions, dental appointments and instructions that require performing some basic mathematical operations [17].

First, the English version of OHLI was modified to suit routine dental services in Belarus. Only minor modifications of content were made in order to preserve the instrument's original structure of the passages, including the number of sentences. We changed a few sentences of the reading comprehension section because amalgam fillings are not used in Belarus. In the numeracy section a medication prescription outline was changed to meet the requirements of Belarusian practice. The number of items in each R-OHLI section is the same as that of the OHLI. The Russian version also met the criteria of the cloze procedure [31]. Similar to the OHLI, four possible answers were given for each omitted word. One of these was correct while the others either sounded similar or were grammatically incorrect [17].

The modified English OHLI version was then translated into Russian by one of the authors (a native Russian speaker), following by back-translation (made by an independent translator with high proficiency in both Russian and English languages). Two translators evaluated the equivalence between the original and back-translated versions, and they concluded that the quality of translation was good.

No time limitation was set for completing the R-OHLI. The R-OHLI items were scored in the same way as the original OHLI [17]; each item was scored with 1 if correct or 0 if not correct or unanswered. The final scores for each section were a sum of each item. As with the original OHLI [17], the scores of the reading comprehension and numeracy sections were multiplied by 1.316 (50/38) and 2.632 (50/19), respectively. Hence, possible weighted scores of each section ranged from 0 to 50 , and the possible total R-OHLI score ranged from 0 to 100 (the sum of the reading comprehension and numeracy sections).

We obtained permission from D. Sabbahi to translate the OHLI into Russian language. The R-OHLI is available upon request from the corresponding author.

\section{Statistical analysis}

Statistical analyses included bivariate and multivariate methods. The readability level of the R-OHLI reading comprehension section was evaluated with Flesch Reading Easy (FRE) scores [32], modified for the Russian language [33].

Internal consistency was assessed with Chronbach's alpha. Ten participants, who agreed to attend the hospital one more time for retesting, completed the R-OHLI once again two weeks after their first visit. The intra-class correlation (ICC) was used to evaluate test-retest reliability.

Concurrent validity (how well a test has an ability to distinguish between characteristically different groups [34]) was verified by comparing the R-OHLI scores between groups with different socio-demographic and oral health behavioral characteristics using independent $t$-tests. To verify construct validity (the degree to which a test measures what it is supposed to measure [34]) a Pearson's correlation coefficient between the R-OHLI and the oral health knowledge scores was calculated. Further, an association of the R-OHLI with other variables was analyzed using multiple linear regression. Two multiple linear regression models were built with the R-OHLI scores as an outcome variable. Selection of variables was based on a study by Sabbahi, et al. [17], and we included the same variables in the model to compare between the English and Russian versions' validation results. At the first step, education level and 
regularity of dental visits were included in the model, besides controlling for age and gender (Model 1). Next, the oral health knowledge test score was added to the model (Model 2).

SPSS 17.0 (IBM Inc.) statistical package was used for all statistical analyses.

\section{Results}

\section{Socio-demographics}

All data from subjects who agreed to participate in the study were used for the analysis. In total, 281 participants with a mean age of $33.1 \pm 12.2$ years were included (Table 2). Among participants, $64.1 \%$ were women; mean ages of females and males were $35.9 \pm 12.3$ and $28.0 \pm$ 10.3 years, respectively.

As for education, 69 (24.6\%) respondents had a university or postgraduate degree, 204 (72.6\%) graduated from high school and $8(2.8 \%)$ participants had only a compulsory, junior high school education. The respondents were divided into two education level groups: with and without a university degree. There was no significant distributional difference in the education level by gender; $26.1 \%$ of female and $21.8 \%$ of male participants had a university diploma. The mean ages of participants with and without a university education were $35.3 \pm 11.3$ and $32.3 \pm 12.4$ years, respectively, and were not significantly different.

\section{Oral health behavior}

People who visited a dentist once a year or more were considered to be regular dental visitors. The proportions of participants who visited a dentist regularly and those who did not were almost equal; $51.6 \%$ of subjects visited a dentist on a regular basis. The mean ages of regular and non-regular dental visitors were $33.4 \pm 12.7$ and $32.8 \pm$ 11.7 years, respectively, and they were not significantly different. However, female participants visited a dentist significantly more regularly than males; $58.9 \%$ of females

Table 2 Sample characteristics of the study subjects

\begin{tabular}{ll}
\hline $\begin{array}{l}\text { Age, years } \\
\quad \text { Mean age (SD) }\end{array}$ & $\mathbf{n = 2 8 1}$ \\
$\begin{array}{l}\text { Gender, \% }(n) \\
\quad \text { Male }\end{array}$ & $33.1(12.2)$ \\
$\quad$ Female & $35.4 \%(101)$ \\
Education level, \% ( $n)$ & $64.1 \%(180)$ \\
$\quad$ High school or less & \\
$\quad$ University or higher & $75.4 \%(212)$ \\
Regularity of dental visits, \% ( $n)$ & $24.6 \%(69)$ \\
$\quad$ Non-regular (less than once a year) & \\
$\quad$ Regular (once a year or more) & $48.4 \%(136)$ \\
\hline
\end{tabular}

and $38.6 \%$ of males visited a dentist at least once a year $(p<0.01)$.

\section{Oral health knowledge test}

The mean oral health knowledge score was $63.8 \pm 16.9$. Oral health knowledge was significantly associated with socio-demographic characteristics (gender, education) and regularity of dental visits (Table 3 ). Female participants, individuals with a university degree or regular dental visitors had significantly $(p<0.01)$ higher oral health knowledge test scores compared to their counterparts.

\section{R-OHLI}

The distribution of the R-OHLI scores was skewed a little to the left, with the majority of participants having high R-OHLI scores (Figure 1), but it did not depart far from a normal distribution (skewness -1.1, kurtosis 0.9). The mean total R-OHLI score was $77.2 \pm 14.5$, the mean reading comprehension and numeracy scores were $39.5 \pm 7.5$ and $37.8 \pm 8.8$, respectively.

The FRE readability scores for both the dental caries and periodontal disease passages of the reading comprehension section were higher than 30 (36.8 and 34.7, respectively).

Cronbach's alpha scores were high: 0.853 and 0.815 for reading comprehension and numeracy sections, respectively, and 0.895 for the total R-OHLI. The intra-class correlation (ICC) values showed good agreement between test-retest results $(n=10)$. The ICC for reading comprehension was 0.899 with a $95 \% \mathrm{CI}$ from 0.647 to 0.974 . The ICC for the numeracy section was 0.637 , with a $95 \%$ CI from 0.056 to 0.896 , and the ICC for the total R-OHLI was 0.875 with a $95 \%$ CI from 0.577 to 0.967 .

To determine concurrent validity the mean R-OHLI scores were compared by socio-demographic and health behavioral characteristics. Females, participants with a university degree or those who visited a dentist at least once a year had significantly $(p<0.05)$ higher mean scores in each section and the total R-OHLI compared to their counterparts (Table 3 ).

As for construct validity, the Pearson's correlation coefficient showed that the R-OHLI was significantly $(p<0.001)$ correlated to the oral health knowledge test (Table 4). The highest correlation coefficient $(r=0.401)$ of the R-OHLI was with the reading comprehension section.

The first multiple linear regression model, including socio-demographic and behavioral factors, showed the R-OHLI scores to be significantly associated with participant's gender and education level (Table 5). Inclusion of the oral health knowledge scores in the model raised the adjusted coefficient of determination (adjusted $\mathrm{R}^{2}$ ) from 0.086 (Model 1) to 0.157 (Model 2) indicating that 16\% of the variance of the R-OHLI scores was explained by Model 2. Multiple regression analysis found the R-OHLI and the oral health knowledge test to be significantly 


\begin{tabular}{|c|c|c|c|c|c|c|}
\hline & & $n$ & $\begin{array}{c}\text { Oral health knowledge } \\
\text { test (10 items) }\end{array}$ & $\begin{array}{l}\text { R-OHLI reading comprehension } \\
\text { section (38 items) }\end{array}$ & $\begin{array}{l}\text { R-OHLI numeracy } \\
\text { section (19 items) }\end{array}$ & $\begin{array}{l}\text { R-OHLI total } \\
\text { (57 items) }\end{array}$ \\
\hline \multirow[t]{3}{*}{ Gender } & Male & 101 & $59.8 \pm 17.2$ & $37.3 \pm 8.3$ & $36.3 \pm 9.2$ & $73.6 \pm 15.4$ \\
\hline & Female & 180 & $66.1 \pm 16.3$ & $40.6 \pm 6.7$ & $38.7 \pm 8.4$ & $79.3 \pm 13.6$ \\
\hline & $p$-value & & $<0.01$ & $<0.01$ & $<0.05$ & $<0.01$ \\
\hline \multirow[t]{3}{*}{ Education } & High school & 212 & $61.1 \pm 16.3$ & $38.5 \pm 7.8$ & $36.7 \pm 9.2$ & $75.2 \pm 15.1$ \\
\hline & University & 69 & $72.0 \pm 15.6$ & $42.4 \pm 5.6$ & $41.1 \pm 6.3$ & $83.5 \pm 10.0$ \\
\hline & $p$-value & & $<0.001$ & $<0.001$ & $<0.001$ & $<0.001$ \\
\hline \multirow[t]{3}{*}{ Regularity of dental visits } & Non-regular & 136 & $59.8 \pm 16.3$ & $38.4 \pm 7.2$ & $36.7 \pm 9.0$ & $75.1 \pm 14.8$ \\
\hline & Regular & 145 & $76.6 \pm 16.6$ & $40.4 \pm 7.4$ & $38.9 \pm 8.5$ & $79.3 \pm 14.0$ \\
\hline & $p$-value & & $<0.001$ & $<0.05$ & $<0.05$ & $<0.05$ \\
\hline
\end{tabular}

associated, even adjusting for socio-demographic and oral health behavioral factors $(p<0.001)$.

\section{Discussion}

Little information is available on the oral health knowledge and literacy status of Russian-speaking populations. Currently, no health literacy instrument is available in the Russian language, which is the $5^{\text {th }}$ most spoken language in the world by total number of speakers and one of the six official languages of the United Nations. Thus, creation and validation of an oral health literacy instrument is the first step in any oral health literacy study among adult Russian speakers.

A considerable number of oral health literacy tools have been developed [7,13,17-19,22-26], and all of them measure different aspects of oral health literacy or use diverse items. Hence, it is difficult to compare results from previously conducted studies. Furthermore, there is

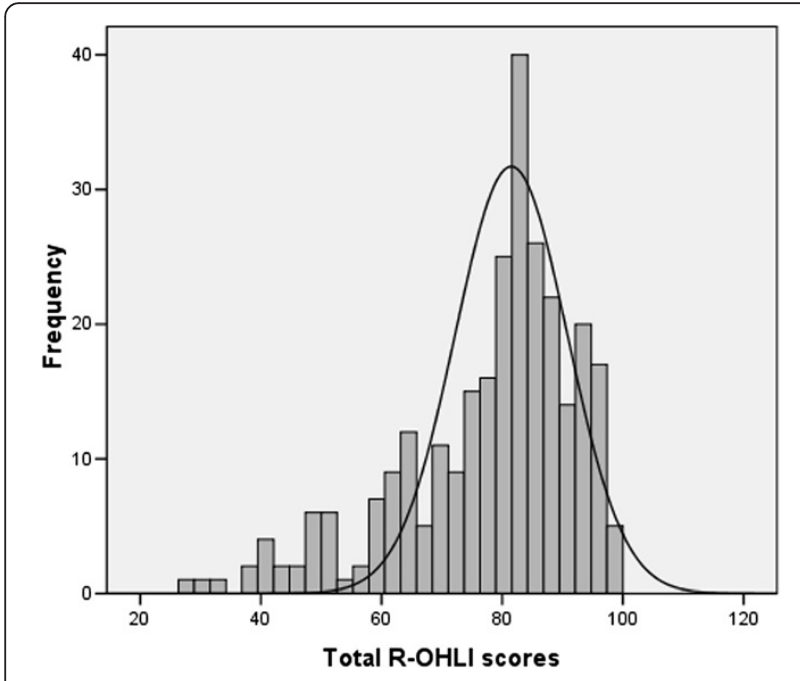

Figure 1 Histogram of the distribution of the R-OHLI scores. no consensus on what level of oral health literacy is "low" or "high"; even the REALD-30, the most widely used oral health literacy test, has no pre-established cut-off points [22].

English word recognition instruments, based on the correct pronunciation, could not be used because of the more regular phonetic structure of the Russian language. Therefore, we adapted an existing reading comprehension tool, the OHLI [17], for Russian speakers with the least possible content modification, instead of creating a new oral health literacy instument. In this paper we examined the reliability and validity of the first functional oral health literacy instrument in Russian, the R-OHLI.

The readability scores indicated that the R-OHLI reading-comprehension section's text did not require the reader to have a university degree to understand its content, thus the readability of the R-OHLI was appropriate for an average adult. Even though scores were lower than those of the original version [13], we deemed readability of the R-OHLI satisfactory. In Belarus, the literacy rate in the general population is 99.6\% [27]. Compulsory education is 9 years long, from primary to junior high school, and the average length of schooling is 16 years [27]. Therefore, reading ability was assumed to be good among Belarusians. In fact, no participants reported any problems understanding the questionnaire's content.

In the present study, the R-OHLI showed good internal consistency by Cronbach's alpha and test-retest reliablity by the ICC. These results were in line with reliability characterictics of the original English version of the OHLI [17]. Thus, the translation process and necessary content modifications did not significanlty alter the questionnaire's original reliability.

Concurrent validity of the R-OHLI was proved by comparing oral health literacy scores between groups with different gender, education level and dental-visits frequency. Although previous studies did not find a significant 
Table 4 Pearson's correlation coefficients (CC) between $\mathrm{R}-\mathrm{OHLI}$ and oral health knowledge test

\begin{tabular}{lcc}
\hline & CC $(\boldsymbol{n}=\mathbf{2 8 1})$ & $\boldsymbol{p}$-value \\
\hline Reading comprehension section (38 items) & 0.401 & $<0.001$ \\
Numeracy section (19 items) & 0.258 & $<0.001$ \\
Total R-OHLI (57 items) & 0.363 & $<0.001$ \\
\hline
\end{tabular}

difference in oral health literacy level between the sexes, gender was significantly associated with the R-OHLI scores in the present study, both in bivariate and multivariate analyses. The higher oral health literacy among female participants in the present study may be attributed to confounding factors that were not included in the analysis, such as health information-seeking behaviors, higher exposure to health related information during pregnancy, and frequent utilization of medical facilities with small children.

Similar to the previous studies, we found participants with a higher education to have higher oral health literacy scores [7,9,15-17,22,26,27]. The effect of education on oral health literacy level remained significant after adjusting for age, gender, regularity of dental visits and oral health knowledge in the multivariate analysis. Regularity of dental visits was a significant factor for oral health literacy in the univariate analysis, as reported by other researches $[14,17,22]$. However, its effect disappeared after including socio-demographic factors in the multuvatiate analysis. Thus, socio-demographic factors may play a role in the relationship between oral health literacy and dentalvisits pattern.

Like the original OHLI, the R-OHLI was significantly correlated with an oral health knowledge test [17]. This significant correlation can be explained by Baker's model of health literacy [1], where conceptual health knowledge is seen as a necessary background for an individual's health literacy.

This study proved the Russian version of the OHLI to be reliable and valid. The R-OHLI is a long questionnaire and requires significant time to be completed (about 20-30 minutes on average). For that reason its application for clinical practice may be limited. However, it was

Table 5 Multiple linear regression results of the R-OHLI scores

\begin{tabular}{lcccccccc}
\hline & \multicolumn{3}{c}{ Model 1 } & & \multicolumn{3}{c}{ Model 2 } \\
\cline { 2 - 4 } \cline { 8 - 9 } & S.E. & Beta & $\boldsymbol{p}$ & & S.E. & Beta & $\boldsymbol{p}$ \\
\hline Age & 0.1 & 0.0 & 0.980 & & 0.1 & -0.0 & 0.970 \\
Gender & 1.8 & 0.2 & 0.008 & & 1.8 & 0.1 & 0.036 \\
Education & 1.9 & 0.2 & 0.000 & & 1.9 & 0.2 & 0.008 \\
Regularity of dental visits & 1.7 & 0.1 & 0.157 & & 1.7 & 0.0 & 0.558 \\
Oral health knowledge & - & - & - & 0.1 & 0.3 & 0.000 \\
\hline
\end{tabular}

confirmed to be a useful research tool to assess the functional oral health literacy among adults.

Certain limitations should be acknowledged. To date, no health literacy instruments exists in Russian, therefore, it was not possible to analyze associations between general health and oral health literacy in this study to evaluate convergent (the degree to which two different instruments measuring theoretically related constructs are in fact related) and predictive (the extent to which an instrument predicts scores on some related criterion) validity [34]. The oral health knowledge test used to establish the construct validity was not validated, which could influence study results. Internal consistency was established with a limited number of participants, which resulted in a relatively high ICC confidence interval. In addition, the information was collected from a convenience sample of patients aged 18-60 years who visited a dental clinic. Therefore, they are likely to have higher oral health literacy than the population in general, especially with the study's exclusion of older people. Future research using a general population sample will be necessary to examine the association of oral health literacy with oral health outcomes, to further scrutinize validity, and to determine cut-off points for the R-OHLI scale.

\section{Conclusions}

We developed a Russian version of the OHLI and evaluated its reliability and validity on dental patients. The R-OHLI showed good internal consistency and test-retest reliability. The R-OHLI scores were significantly associated with socio-demographic and behavioral factors in bivariate analyses. Moreover, the multivariate analysis found a significant association between the R-OHLI and the oral health knowledge test results. Therefore, it was concluded that the R-OHLI is a reliable and valid oral health literacy assessment instrument for Russian-speaking people.

\section{Competing interests}

The authors declare that they have no competing interests.

\section{Authors' contributions}

$\mathrm{AB}$ conceived the study, participated in its design and coordination, collected data, performed statistical analysis and wrote the manuscript draft. MU participated in the study design, assisted in interpretation of the data, coordinated statistical analysis, and revised the manuscript. SF conceived the study, made substantial contributions to study design, and participated in the study implementation. YK contributed to the study protocol and data collection, coordinated the study implementation, statistical analysis and interpretation of the results, and revised the manuscript. All authors read and approved the final manuscript.

\section{Acknowledgements}

This study was partly supported by Futokukai foundation by Lion Medical Corporation (Tokyo, Japan). We gratefully acknowledge the work of Dr. Dania A. Sabbahi and colleagues who developed the original OHLI and gave us the opportunity to create its Russian version.

Received: 23 April 2014 Accepted: 20 November 2014 Published: 27 November 2014 


\section{References}

1. Baker DW: The meaning and the measure of health literacy. J Gen Intern Med 2006, 21(8):878-883.

2. Nutbeam D: The evolving concept of health literacy. Soc Sci Med 2008, 67(12):2072-2078.

3. Petersen PE: The World Oral Health Report 2003: continuous improvement of oral health in the 21st century-the approach of the WHO Global Oral Health Programme. Community Dent Oral Epidemiol 2003, 31(Suppl 1):3-23.

4. Ratzan S, Parker R: Introduction. In National Library of Medicine Current Bibliographies in Medicine: Health Literacy. Volume NLM Pub. No. CBM 2000-1. Edited by Selden C, Zorn M, Ratzan S, Parker R. Bethesda, MD: National Institutes of Health, U.S. Department of Health and Human Services; 2000.

5. US Department of Health and Human Services: Healthy People 2010. In vol. Vol. Il: Oral Health. 2nd edition. Washington, DC: US Government Printing Office; 2000.

6. National Institute of Dental and Craniofacial Research NloH, U.S. Public Health Service, D.partment of Health and Human Services: The invisible barrier: literacy and its relationship with oral health. A report of a workgroup sponsored by the National Institute of Dental and Craniofacial Research, National Institute of Health, U.S. Public Health Service, Department of Health and Human Services. J Public Health Dent 2005, 65(3):174-182.

7. Atchison KA, Gironda MW, Messadi D, Der-Martirosian C: Screening for oral health literacy in an urban dental clinic. J Public Health Dent 2010, 70(4):269-275

8. Jones M, Lee JY, Rozier RG: Oral health literacy among adult patients seeking dental care. J Am Dent Assoc 2007, 138(9):1199-1208. quiz 1266-1197.

9. Lee JY, Divaris K, Baker AD, Rozier RG, Lee SY, Vann WF: Oral health literacy levels among a low-income WIC population. J Public Health Dent 2011, 71(2):152-160.

10. Lee JY, Divaris K, Baker AD, Rozier RG, Vann WF: The relationship of oral health literacy and self-efficacy with oral health status and dental neglect. Am J Public Health 2012, 102(5):923-929.

11. Sistani MM, Yazdani R, Virtanen J, Pakdaman A, Murtomaa H: Oral health literacy and information sources among adults in Tehran. Iran Community Dent Health 2013, 30(3):178-182.

12. Horowitz AM, Kleinman DV: Oral health literacy: a pathway to reducing oral health disparities in Maryland. J Public Health Dent 2012, 72(Suppl 1):S26-S30.

13. Macek MD, Haynes D, Wells W, Bauer-Leffler S, Cotten PA, Parker RM: Measuring conceptual health knowledge in the context of oral health literacy: preliminary results. J Public Health Dent 2010, 70(3):197-204.

14. Ueno M, Takeuchi S, Oshiro A, Kawaguchi Y: Relationship between oral health literacy and oral health behaviors and clinical status in Japanese adults. J Dental sci 2013, 8(2):170-176.

15. Vann WF, Lee JY, Baker D, Divaris K: Oral health literacy among female caregivers: impact on oral health outcomes in early childhood. $J$ Dent Res 2010, 89(12):1395-1400.

16. Divaris K, Lee JY, Baker AD, Vann WF: Caregivers' oral health literacy and their young children's oral health-related quality-of-life. Acta Odontol Scand 2012, 70(5):390-397.

17. Sabbahi DA, Lawrence HP, Limeback H, Rootman I: Development and evaluation of an oral health literacy instrument for adults. Community Dent Oral Epidemiol 2009, 37(5):451-462.

18. Wong HM, Bridges SM, Yiu CK, McGrath CP, Au TK, Parthasarathy DS: Validation of the Hong Kong Oral Health Literacy Assessment Task for paediatric dentistry (HKOHLAT-P). Int J Paediatr Dent 2013, 23(5):366-375.

19. Wong HM, Bridges SM, Yiu CK, McGrath CP, Au TK, Parthasarathy DS: Development and validation of Hong Kong Rapid Estimate of Adult Literacy in Dentistry. J Invest Clin Dent 2012, 3(2):118-127.

20. Kickbusch I, Pelikan JM, Apfel F, Tsouros AD, World Health Organization. Regional Office for Europe: Health literacy: The solid facts. Copenhagen: WHO Regional Office for Europe; 2013.

21. Kondilis BK, Kiriaze IJ, Athanasoulia AP, Falagas ME: Mapping health literacy research in the European Union: a bibliometric analysis. PLoS One 2008, 3(6):e2519.

22. Lee JY, Rozier RG, Lee SY, Bender D, Ruiz RE: Development of a word recognition instrument to test health literacy in dentistry: the REALD-30-a brief communication. J Public Health Dent 2007, 67(2):94-98
23. Richman JA, Lee JY, Rozier RG, Gong DA, Pahel BT, Vann WF: Evaluation of a word recognition instrument to test health literacy in dentistry: the REALD-99. J Public Health Dent 2007, 67(2):99-104.

24. Stucky BD, Lee JY, Lee SY, Rozier RG: Development of the two-stage rapid estimate of adult literacy in dentistry. Community Dent Oral Epidemiol 2011, 39(5):474-480.

25. Gong DA, Lee JY, Rozier RG, Pahel BT, Richman JA, Vann WF: Development and testing of the Test of Functional Health Literacy in Dentistry (TOFHLiD). J Public Health Dent 2007, 67(2):105-112.

26. Naghibi Sistani MM, Montazeri A, Yazdani R, Murtomaa H: New oral health literacy instrument for public health: development and pilot testing. $J$ Invest Clin Dent 2014, 5(4):313-321.

27. Lee J, Stucky B, Rozier G, Lee SY, Zeldin LP: Oral Health Literacy Assessment: development of an oral health literacy instrument for Spanish speakers. J Public Health Dent 2013, 73(1):1-8.

28. Lewis PM, Simmons GF, Fennig CD: Ethnologue: Languages of the World. Seventeenthth edition. Dallas, Texas: SIL International; 2013.

29. Burceva E: Forms of work with the text in the formation of the text of skills of schoolchildren (In Russian). TSPU Bulletin 2013, 3(131):202-206.

30. Parker RM, Baker DW, Williams MV, Nurss JR: The test of functional health literacy in adults: a new instrument for measuring patients' literacy skills. J Gen Intern Med 1995, 10(10):537-541.

31. Newby D: 'Cloze' procedure refined and modified. 'Modified Cloze', 'reverse Cloze' and the use of predictability as a measure of communication problems in psychosis. Br J Psychiatry 1998, 172:136-141.

32. Flesch R: A new readability yardstick. J Appl Psychol 1948, 32(3):221-233.

33. Oborneva I: Automated assessment of the textbooks' readability based on a statistical analysis (In Russian). Moskow: Russian Academy of Education; 2006

34. Babbie E: The practice of social research. 13th edition. Belmont, CA: Wadsworth; 2013.

doi:10.1186/1472-6831-14-141

Cite this article as: Blizniuk et al.: Evaluation of a Russian version of the oral health literacy instrument (OHLI). BMC Oral Health 2014 14:141.

\section{Submit your next manuscript to BioMed Central and take full advantage of:}

- Convenient online submission

- Thorough peer review

- No space constraints or color figure charges

- Immediate publication on acceptance

- Inclusion in PubMed, CAS, Scopus and Google Scholar

- Research which is freely available for redistribution

Submit your manuscript at www.biomedcentral.com/submit
C) Biomed Central 